\title{
Physical Concepts about Telecommunications Theory Focusing on Knowledge Application
}

\author{
Oscar H. Salinas ${ }^{1}$, Angel Estrada Arteaga ${ }^{2}$, Martha E. Luna Ortíz ${ }^{1}$, \\ Marco A. Amado González ${ }^{1}$ \\ ${ }^{1}$ Academic Division of Information and Communication Technologies, Universidad Tecnológica \\ Emiliano Zapata del Estado de Morelos, Emiliano Zapata, México \\ ${ }^{2}$ Software Development Center, Universidad Tecnológica Emiliano Zapata del Estado de Morelos, Emiliano \\ Zapata, México \\ Email: oscarsalinas@utez.edu.mx
}

Received November $6^{\text {th }}$, 2013; revised December $6^{\text {th }}, 2013$; accepted December $13^{\text {th }}, 2013$

Copyright (C) 2014 Oscar H. Salinas et al. This is an open access article distributed under the Creative Commons Attribution License, which permits unrestricted use, distribution, and reproduction in any medium, provided the original work is properly cited. In accordance of the Creative Commons Attribution License all Copyrights (C) 2014 are reserved for SCIRP and the owner of the intellectual property Oscar H. Salinas et al. All Copyright (C) 2014 are guarded by law and by SCIRP as a guardian.

Teaching telecommunications theory for Engineering Technologies Information students can be viewed as an interesting challenge. This is mainly due to Telecommunications theory which integrates knowledge about two basic sciences: physics and mathematics. The proposal explained in this paper focused on obtaining and deeply understanding the physical concepts related to the theory of telecommunications, rather than memorizing equations, which most of the time would not make sense for students. Engineering students' work focusing on learning the physical and mathematical concepts, was able to design and develop academic tools with two important characteristics for Universities with low budget: easy to use and inexpensive. Therefore, the teaching-learning process is more efficient being adjusted to their endemic circumstances about understanding, knowledge application and few economic resources. Moreover those students were facing less problems understanding and handling the mathematical equations related to the telecommunications theory. Following the proposed procedure, students have designed and built academic tools, such as videos, crosswords, C\# applications, graphing on worksheets, and so on. To monitor progress weekly, evaluation was conducted using questionnaires without equations, which were evaluated by the students themselves. Electronic and pedagogical tools were combined to design specific audiovisual aids to facilitate and assure that students were obtaining and retaining those physical and mathematical concepts before starting the equations handling. A comparison was done about groups working under two scenarios: the one described above and the other called in this report "traditional". A drastic difference about student's grades between two groups was observed.

Keywords: Physics; Telecommunications; Electromagnetic Theory; Pedagogical; Software; Learning Styles

\section{Introduction}

Learning telecommunications theory is not an easy task for young students of Engineering of Information Technologies. Like any other technological field, it is based on Physics and Mathematics science. Telecommunications theory can be understood by knowing their physical phenomena and mathematical equations related to it. The complexity of the theory behind the telecommunications theory could be based on the fact that it integrates different knowledge disciplines working together, which gives a very interesting and challenging field to know. For example, for Engineering Technologies Information students, it is very hard to understand that electronics is a branch of physics (Tan, 2010), and unfortunately, for some of them, most of the current telecommunications systems are based on electronics devices. Telecommunications systems are formed basically by three components, transmitter, channel of transmission or propagation, and receiver. Learning about how each of them works depends on the conceptualization of the theory behind them. For most of the students, the understanding concepts of physics behind the data transmission, propagation and reception, and the relationship between them and their related mathematics, is not as easy as it can be read. In the field of wireless telecommunications, the communication channel is mainly the air, so the communication between the transmitter and receiver is through antennas. The antenna behavior and wireless communication are described by electromagnetic theory (García et al., 2010; Leppavirta et al., 2011). Understanding concepts about electronics and electromagnetic theory give Engineering Technologies Information students a deep overview about their application field. A deep understanding of concepts is very important before starting handling mathematical equations. There is a lot of work developed to enhance the teaching-learning process in this academic field (Tan, 2010; García et al., 2010; Leppavirta et al., 2011, Fernández-Sánchez et al., 2011; Hinojo et 
al., 2011; Weyten et al., 2011; Vergata, 2012; Chen et al., 2010; Linn et al., 2012; Taslidere, et al. 2011; Dawy et al., 2010), such as interactive laboratories (Fernández-Sánchez et al., 2011; Hinojo et al., 2011; Weyten et al., 2011; Vergata, 2012), low cost laboratories where students can put hands on practice (Chen et al., 2010; Linn et al., 2012; Taslidere et al., 2011), applications for mobile handsets (Dawy et al., 2010), are some of the creative ideas. On the other hand, students must feel interested and motivated to learn a specific topic or subject of their academicals program. This also includes another learning area like mathematics (Salinas, 2013). The motivation aspect is part of the professor's job; they must have different tools or ways to stimulate student interest. Another important aspect is the student's involvement; students must be part of the teaching-learning process, acting not as a passive element, but as an active one. Combination of these two key aspects gives the students a wide open picture about what they are learning. An efficient way to do it is based on student's hands on tools hardware or software, so they can stimulate themselves interest in the topic that they are learning. Working under this scenario, students are able by themselves to do the possible practical applications of the theory they have been reviewed. Nevertheless in some countries the universities budgets are not sufficient to have high tech laboratories. This is why professors and students need to work together and make their imagination their main tool to design efficient and low cost tools for academic purposes.

\section{Metodology}

Two groups were selected to perform the test concept: one working under the proposal scenario and the other one working under a scenario called traditional in this report. The proposal scenario was described above, and the traditional includes the following characteristics: Professor teaches the corresponding topic of the subject and students take notes, i.e they just act as knowledge receptors; professor solves some academic problems on the blackboard; students solve another academic problems either individually or in team; professor leaves some homework that review it and grade it later; professor applies the written exam according with the date scheduled. Under this scenario there are no conditions for student's motivation and no student involvement in the teaching-learning process. The proposal scenario involves the student in a more intimate way, becoming the responsible of its own learning. The purpose is not just involving the students in their learning process, but they also can be able to develop some academic tools, for them and for the next generations. There is not a sequence or a recipe about the tools design and development process, professor must keep in mind that students have different learning skills, even though they are reviewing the same topic. Therefore academic tools must be designed by them, based on the best way they can work developing tools to understand the concepts behind theory or equations. The response variable to compare the level of concepts understanding was the grades they obtain solving a traditional exam, it means an exam containing some academic and practical problems. They needed to demonstrate that they were able to identify the necessary theoretical tools to solve both kinds of problems. The proposal hypothesis is that it can be achieved as easy as they have a deep understanding of Physical concepts.

\section{Results}

The deliverables of the activities from students includes: C\# applications, Figure 1, academic videos explaining a specific topic, Figure 2 (Morelos, Youtube, 2011; Morelos, 2012; Morelos, Youtube, 2011; Morelos, Youtube, 2011; Morelos, Youtube, 2011; Morelos, Youtube, 2011; Morelos, Youtube, 2012), crosswords puzzles containing all the concepts reviewed, Figure 3, graphics in spreadsheet explaining the meaning of a key point in the graph, Figure 4. For example about the optical fiber, it's very important to understand the properties of light, specifically the total internal reflection phenomenon and therefore the critical angle, that is calculated with (following the Snell's Law),

$$
\theta_{C}=\sin ^{-1}\left(\frac{n_{2}}{n_{1}}\right)
$$

Working in this way, students who have skills for developing

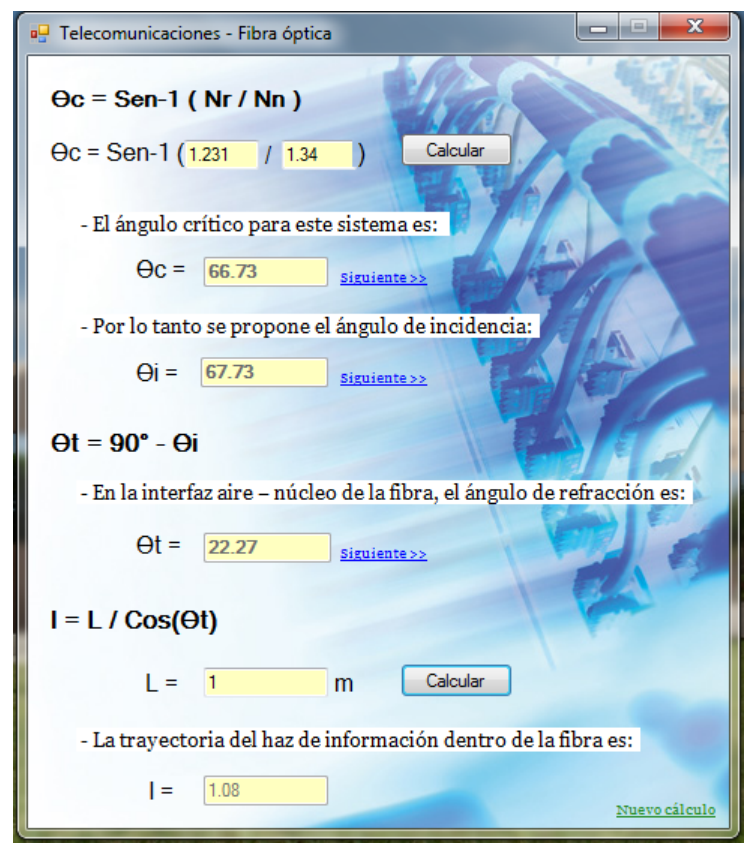

Figure 1.

Calculator of critical angle, path length traversed and number of reflections inside of an optical fiber.

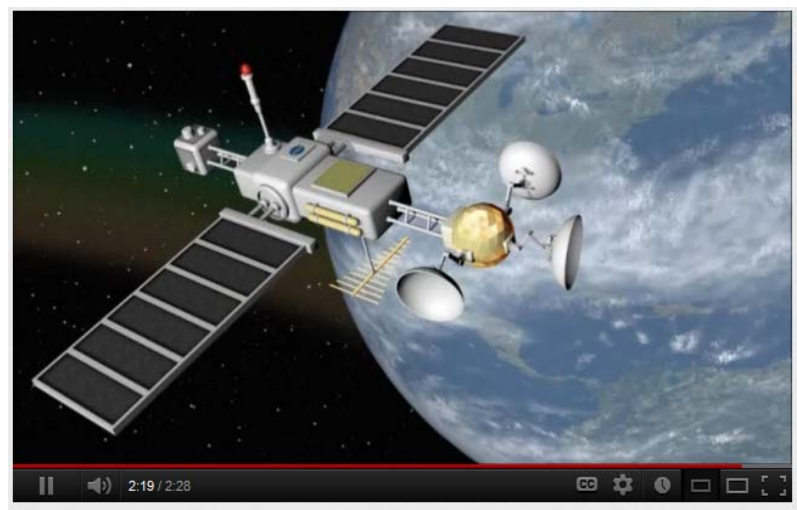

Figure 2.

Video explaining basic concepts about satellite telecommunications. 


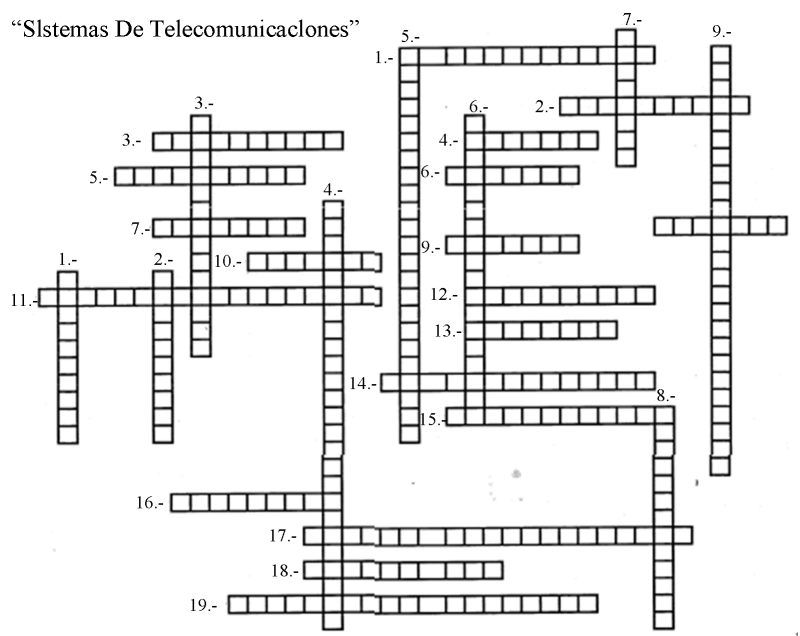

Figure 3.

Electromagnetic wave parameters concepts in a crossword puzzle.

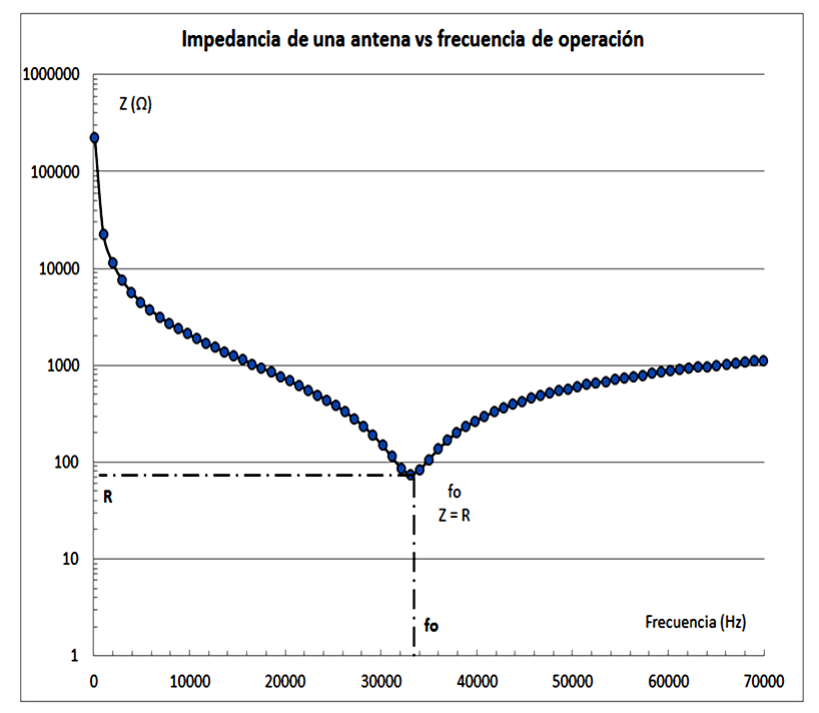

Figure 4.

Antenna minimum losses condition on a graphical demonstration.

software tools were able to identify by themselves that is very helpful for them to develop a basic calculator, Figure 1. The difference with some of the ones available is that this one is designed and tailored of the necessities of their own academic environment. The basic calculator was developed to calculate some important parameters about telecommunications systems based on optical fiber. The first calculation of the C\# application is the critical angle. For the optical fiber, $n_{2}$ and $n_{1}$ are the refractive index of the cladding and core, respectively. There is an important concept behind the critical angle equation: $n_{2}$ must be lower than $n_{1}$; otherwise calculation tool gives a mathematical error. Student must understand this concept and the reason why a mathematical error is obtained if the condition is not accomplished. C\# Application must alert the user about possible errors introducing data, asking the classic question: "Are you sure about the data?” for example. C\# application also calculates the path length traversed and the number of reflections inside the optical fiber. It helps students to understand deeply the total internal reflection concept and how the optical fiber works.

Students also make some academic videos explaining with their own words some basic concepts about satellite telecommunications systems (Morelos, Youtube, 2011). Figure 2 shows an example of them. Videos have two academic purposes: one is just for general explanation about a specific telecommunication system (Morelos, Youtube, 2011), and the other one is like video tutorials, explaining the topics or how to do a graphic in a worksheet (Morelos, Youtube, 2012).

Another tool developed by the students was the crossword puzzle designing, one of them is showed in Figure 3. Students must describe the word to be written using colloquial language; it means not the one found in the literature but the one they use to speak.

About antenna behavior is necessary to understand the electromagnetic theory, in some universities it is coursed in more than one semester (Leppavirta et al., 2011), so there is a lot of time to get the whole theory. In this case students must learn about antenna behavior in about six weeks. Therefore it is very important to focus in the main antenna parameters and the concepts behind them. Sometimes this is done by designing a virtual wireless system (Hinojo et al., 2011), virtual signal analysis (Vergata, 2012), building the whole wireless telecommunication system (Chen et al., 2010), or a low cost laboratory for specific frequency range (Linn et al., 2012; Taslidere et al., 2011; Dawy et al., 2010). However before doing that it is very important to understand an important parameter about antenna behavior, the impedance (Z, units in Ohms). Impedance depends on the operating frequency as described by,

$$
Z=\sqrt{R^{2}+\left(2 \pi f L-\frac{1}{2 \pi f C}\right)^{2}}
$$

where $Z$ is the magnitude of impedance, $R$ is the resistance (real part of impedance), $f$ is frequency, $L$ is the associated inductance and $C$ is the associated capacitance. The point marked as $f_{0}$ (resonance frequency) in the graph, Figure 4, is the main purpose for making the graph. The important concept in this case is the meaning of $Z=R$ (Morelos, Youtube, 2011). Students must keep in mind why antenna impedance is equal to its resistance and what are the implications about antenna performance. At that point the total reactance (imaginary part of the impedance) is zero: the associated inductance and the capacitance have the same value and eliminated each other (Morelos, Youtube, 2012). When students observe graphically that there is a point when occurs minimum impedance, they are able to relate it with a minimum losses condition by themselves. Therefore the concept of resonance frequency is easier to be understood. Once this concept and the other ones related to it are deeply understood, applying software (Hinojo et al., 2011; Vergata, 2012) or hardware (Linn et al., 2012; Taslidere et al., 2011; Dawy et al., 2010) to design a wireless system is easier. Students from the two groups were used as the experimental sample; future work must be developed in the same aim to get more data. Students from Group A were working under the traditional scenario. Students from Group B were working under the interactive model, developing academic tools as was explained before. The response variable was the course grade of each students' group, Figure 5. The evaluation scale is: NA, not approved (less than 8), $\mathrm{SA}=8, \mathrm{DE}=9, \mathrm{~A}=10$, compared with a zero to ten scales. SA means satisfactory performance, $\mathrm{DE}$ means achiever performance, and AU self-sufficient performance. 


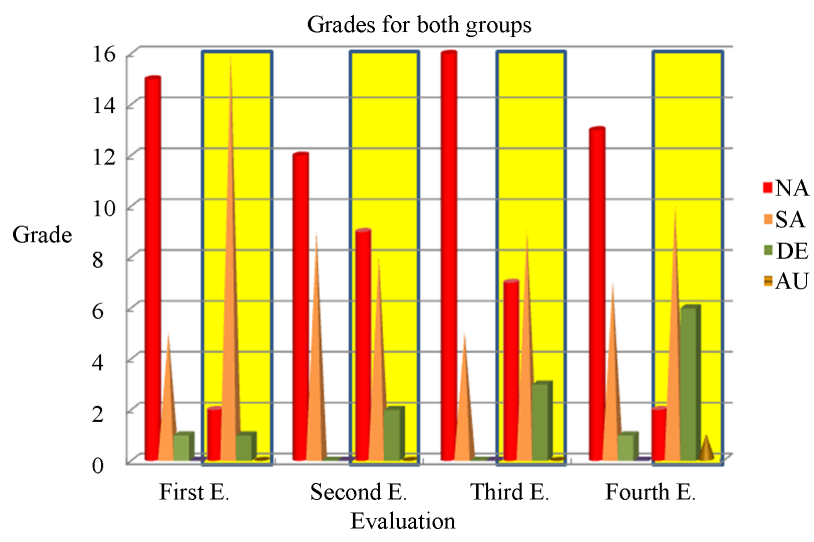

Figure 5.

Comparison of grades obtained from control and experimental group.

Results in the shadow rectangle are from Group B, the control one. A drastic difference between the two groups can be observed. The exam is basically composed of problems that involve handling of equations where the students need to understand what the problem is asking and what they need to know to solve it. It means the student must have a deep understanding of physical concepts behind the equation. Most of the students of control group have got NA, while the experimental Ones are in SA average; it means focusing in the concepts helps increase the understanding of the theory and therefore their course grades. Around $2.4 \%$ of students from Group A have obtained DE, while 15.8 \% from Group B have obtained the same grade. A drastic difference is founded analyzing this specific grade. From Group A 33.33\% of students have approved (grades above SA), on the other hand $73.7 \%$ of the students of group B have approved, i.e. more than twice. Nevertheless just $1.32 \%$ of students achieve the AU grade. More work needs to be done in the aim to increase the AU percentage, which basically means the students get involved in their learning process as an active actor, and consequently they will get higher courses grades. It can be said that a combination of student motivation and their active involvement in the teaching-learning process it is possible to improve their understanding of a topic as difficult as telecommunications.

\section{Acknowledgement}

To all the students who have been designing and developing the tools presented in this work and supporting the proposal, for their really important feedback to improve some activities and teaching techniques or suggesting others to be incorporated. To all of the teachers that have done great efforts about the teaching-learning process improvement, trying to design more efficient academic tools and ease to use.

\section{REFERENCES}

Taslidere, E., Cohen, F. S., \& Reisman, F. K. (2011). Wireless sensor netwotks-A hands on modular experiments platform for enhaced pedagogical learning. IEEE Transactions on Education, 54, 24-33. http://dx.doi.org/10.1109/TE.2010.2041235

García, J., \& Hernández, A. (2010). Active Methodologies in a Queueing Systems Course for Telecommunication Engineering Studies. IEEE Transactions on Education, 53, 405-412. http://dx.doi.org/10.1109/TE.2009.2026365

Leppavirta, J. Kettunen, H., \& Sihvola, A. (2011). Complex problem exercises in developing engineering students, conseptual and procedural knowledge of electromagnetics. IEEE Transactions on Education, 54, 63-66.

http://dx.doi.org/10.1109/TE.2010.2043531

Hinojo, J. M., et al. (2011). Plaraforma para el aprendizaje de tecnologías inalámbricas y redes de sensores basada enn el sistema open hardware denominado Openmoko. IEEE-RITA, 6, 49-57.

Weyten, L. Rombouts, P., Catteau, B., \& De Bock, M. (2011). Validation of symbolic expressions in circuit analysis e-learning. IEEE Transactions on Education, 54, 564-568. http://dx.doi.org/10.1109/TE.2010.2090882

Linn, Y. (2012). An ultra low cost wireless communications laboratory for education and research. IEEE Transactions en Education, 55, 169-179. http://dx.doi.org/10.1109/TE.2011.2158318

Chen, M. H., et al. (2010). High frequency wireless communication system: $2.45 \mathrm{GHz}$, front-end circuit and system integration. IEEE Transactions on Education, 53, 631-636. http://dx.doi.org/10.1109/TE.2009.2038897

Fernández-Sánchez, P., et al. (2011). SIAPE: Sistema Integrado para el Aprendizaje de la Electrónica para técnicos e ingenieros. IEEE-RITA, 6, 58-63.

Salinas, O. H. (2013). Developing Mathematical Literacy, Based on Elemental Software and Academic Tools Development. Creative Education, 4, 178-180. http://dx.doi.org/10.4236/ce.2013.47A2023

Tan, K. (2010). Bridging physics to electronics-an outreach effort. IEEE Transactions on Education, 53, 3-11. http://dx.doi.org/10.1109/TE.2009.2021850

UTEZ, M. (2011) Youtube. Recuperado el Septiembre de 2011. http://www.youtube.com/watch?v= Mr5J2A-vlA

UTEZ, M. (2011) Youtube. Recuperado el Septiembre de 2011. http://www.youtube.com/watch?v=eIuyBsmKNoY

UTEZ, M. (2011) Youtube. Recuperado el Septiembre de 2011. http://www.youtube.com/watch?v=CBVzNz-ktBI

UTEZ, M. (2011) Youtube. Recuperado el Septiembre de 2012. http://www.youtube.com/watch?v=NgEaq ifIFM

UTEZ, M. (2011) Youtube. Recuperado el Septiembre de 2011. http://www.youtube.com/watch?v=Mr5J2A-vlA

UTEZ, M. ( 2012). Youtube. Recuperado el Septiembre de 2012. http://www.youtube.com/watch?v=XPORIbVDiug\&feature=pclp

UTEZ, M. (2012) Youtube. Recuperado el Octubre de 2012. http/:www.youtube.com/watch?v=J5bddaLBDeI

Vergata, T. (2012) Visual analizer project. Recuperado el 24 de Septiembre de 2012. www.sillanumsoft.org

Dawy, Z., Husseini, A., Yaacoub, E., \& Al-Kanj, L. (2010). A wireless communications laboratory on cellular network planning. IEEE Transactions on Education, 53, 653-661.

http://dx.doi.org/10.1109/TE.2009.2039935 